\title{
Predicting resistance to endocrine therapy in breast cancer: It's time for epigenetic biomarkers (Review)
}

\author{
MÁRIO FONTES-SOUSA ${ }^{1-3^{*}}$, MARIA AMORIM ${ }^{1,4^{*}}$, SOFIA SALTA ${ }^{1}$, SUSANA PALMA DE SOUSA $^{2,3}$, \\ RUI HENRIQUE ${ }^{1,5,6}$ and CARMEN JERÓNIMO ${ }^{1,6}$ \\ ${ }^{1}$ Cancer Biology and Epigenetics Group, IPO Porto Research Center (CI-IPOP); ${ }^{2}$ Department of Medical Oncology; \\ and ${ }^{3}$ Breast Cancer Clinic, Portuguese Oncology Institute of Porto (IPOPorto) 4200-072 Porto; ${ }^{4}$ Master in Oncology, \\ Institute of Biomedical Sciences Abel Salazar-University of Porto (ICBAS-UP), 4050-313 Porto; \\ ${ }^{5}$ Department of Pathology, Portuguese Oncology Institute of Porto (IPOPorto) 4200-072 Porto; \\ ${ }^{6}$ Department of Pathology and Molecular Immunology, Institute of Biomedical Sciences \\ Abel Salazar-University of Porto (ICBAS-UP), 4050-313 Porto, Portugal
}

Received February 7, 2018; Accepted September 12, 2018

DOI: 10.3892/or.2019.6967

\begin{abstract}
Notwithstanding the marked progress in breast cancer (BC) management, it still constitutes the most common malignancy in women and a major cause of morbidity and mortality, thus remaining a major health issue worldwide. Most BC cases are hormone receptor (HR) positive (luminal A or B molecular subtypes) and endocrine treatment (ET) is an important therapeutic modality at all disease stages. Nevertheless, despite substantial improvements in BC patient outcome, effectiveness of ET is limited, as up to $40 \%$ of patients eventually relapse or progress and endocrine resistant $\mathrm{BC}$ has a less favorable prognosis and constitutes a therapeutic challenge. The biological mechanisms underlying endocrine resistance are, however, still poorly understood. In this review, we focused on data regarding the main epigenetic mechanisms associated with the development of endocrine treated-resistant BC described so far, including alterations in DNA methylation, non-coding RNAs, chromatin remodeling, post-translational histone modifications and histone variants. Notably, specific epigenetic alterations have been characterized in this subset of breast tumors and may be of clinical value for individualized patient management in the future.
\end{abstract}

Correspondence to: Professor Carmen Jeronimo, Cancer Biology and Epigenetics Group, IPO Porto Research Center (CI-IPOP), Laboratory 3, F Building, 1st floor; Rua Dr António Bernardino de Almeida, 4200-072 Porto, Portugal

E-mail: carmenjeronimo@ipoporto.min-saude.pt; cljeronimo@icbas.up.pt

*Contributed equally

Key words: breast cancer, epigenetic biomarkers, endocrine therapy, drug resistance, patient management

\section{Contents}

1. Introduction

2. Evidence acquisition

3. Conclusion

\section{Introduction}

Most breast cancers (BC), over 2/3 of cases, express estrogen (ER) and progesterone (PR) receptors (1). This is extremely important since these are used as biomarkers for subtype classification, with implications in choice of treatment and prognosis in BC patients (2). Notably, endocrine therapies (ET) have been successfully used for treating ER positive BC patients with significant impact in patient outcome. Several endocrine drugs are approved for BC treatment, most notably tamoxifen, toremifene, anastrozole, letrozole, exemestane and fulvestrant, which may be used in different clinical contexts, such as chemoprophylaxis, neoadjuvant, adjuvant and palliative treatments. However, the effectiveness of ET is limited as up to $40 \%$ of patients may experience disease recurrence while on ET adjuvant treatment $(1,3)$. Moreover, in the metastatic setting, acquired resistance to ET is virtually an universal feature, and is clinically defined in accordance to the 3rd ESO-ESMO International Consensus Guidelines (4) and many efforts have been made to understand the mechanisms involved in acquisition of acquired resistance to ET. These, however, remain mostly elusive and no biomarkers have been validated in this setting despite intense drug development and approval.

Epigenetics may be defined as mechanisms that regulate cell fate specifications, while the DNA remains unchanged (5). Some of these mechanisms include DNA methylation, non-coding RNAs, chromatin remodeling and histone post-translational modifications or variants. Collectively, these components constitute the epigenome machinery whose role is to define 
which information is available for transcription and for translation (5). DNA methylation is performed by specific enzymes, the DNA methyltransferases (DNMTs) that introduce a methyl group at the 5 ' position of a cytosine ring inside $\mathrm{CpG}$ dinucleotides (6). Globally, promoter methylation of genes is associated with transcription inhibition (6). Furthermore, the N-terminal tails of histones may undergo post-translation modifications that subsequently impact the chromatin structure (7). The most well-studied histone post-translation modifications are histone acetylation and histone methylation. Histone acetylation is associated with gene expression and is carried out by histone acetyltransferases (HATs), while histone deacetylation is accomplished by histone deacetylases (HDACs) (7). Histone methylation, which depending on the residue and the number of methyl groups may lead either to transcription repression or activation (8), is catalyzed by histone methyltransferases (HMTs), while histone demethylation is performed by histone demethylases (HDMs) (7). In addition to post-translational histone modifications, histone variants that can replace canonical histones are an additional level of epigenetic complexity, and contribute to the shaping of the chromatin structure.

Non-coding RNAs (ncRNAs) comprise a hidden layer of internal signals that control various levels of gene expression (9). Among these, microRNAs (miRNAs) and long non-coding RNAs (lncRNAs) are the most frequently reported in BC. IncRNAs are ncRNA molecules usually longer than 200 nucleotides that do not fit into known classes of small or structural RNAs (9) and may act as protein-DNA or protein-protein scaffolds, miRNA sponges, protein decoys, or regulators of translation (10). miRNAs are endogenous, small non-coding single-stranded RNAs with 22 nucleotides in length, that exert a finely tuned regulation of gene expression at the post-transcriptional level (11) by binding to mRNA targets, inducing its cleavage or repressing its translation (11).

Over the last few years, convincing data has suggested that altered epigenetic regulation may be involved in tumor initiation, progression and cancer resistance to therapy, including endocrine resistance, particularly in BC. For instance, ER expression is currently one of the foremost predictive biomarkers of response to ET, and altered expression of ER may be due to hypermethylation of $\mathrm{CpG}$ islands within its promoter, increased histone deacetylase activity in the ESR1 promoter or translational repression by miRNAs (12). Since ER was found to be deleted in only $15-20 \%$ of endocrine-resistant BC, several epigenetic mechanisms may be involved in the development of endocrine treatment-resistance (3), and some of these are depicted in Fig. 1.

Our objective was to review the published evidence regarding epigenetic mechanisms associated to ET resistance in BC, as it may be considered an emerging subject and worth special focus.

\section{Evidence acquisition}

For the selection of the most relevant bibliography, we conducted a PubMed ${ }^{\circledR}$ search using the terms 'endocrine resistance', 'breast cancer' and 'epigenetic mechanisms'. Reference lists from key articles were also searched for additional relevant data. The criteria for article selection were: written in English, central theme based on ET resistance on BC and epigenetic mechanisms.
Original studies were selected based on the detail of analysis, mechanistic support of data, novelty, and potential clinical usefulness of the findings. Chemotherapy/radiotherapy-resistance, HER2-enriched subtype or 'triple negative' BC citations were excluded for being outside the scope of this review.

DNA methylation. DNA methylation is one of the most common epigenetic changes and has been reported in multiple tumors, including BC $(9,13)$. This epigenetic alteration is inherently stable and has been proposed as a promising cancer biomarker in multiple cancers since it can be sampled from less invasive sources such as liquid biopsies (plasma or urine) (13-15). Thus, the role of DNA methylation as a predictor of ET resistance is a field of growing interest and has become the focus of several research teams (16-18) since it may improve BC patients' risk stratification.

Notably, Stone et al reported that in endocrine treated-resistant cell lines, DNA hypermethylation occurs predominantly at estrogen-responsive enhancers, leading to reduced ER binding and subsequently to expression downregulation. Furthermore, luminal subtype BC patients with relapsed disease exhibited significantly higher methylation levels at all enhancer loci studied (19). By comparing anti-estrogen-resistant cell lines with the parental sensitive cell line, DNA methylation of the promoter region of genes was also suggested to play a role in the emergence of endocrine resistance $(17,20)$ (Table I). Multicenter studies, including several cohorts of BC patients were able to confirm these findings. Specifically, PITX2 methylation levels were consistently identified as a valuable biomarker to predict outcome in low-risk BC patients (ER-positive, node-negative) treated with surgery followed by adjuvant tamoxifen $(21,22)$. Nevertheless, multiple validations are still required before the implementation of these markers in the clinical setting (Table I). Thus, to date, no clinical trials have assessed the clinical relevance of these candidate biomarkers.

Non-coding RNAs. As previously mentioned, decreased ER expression may be due to post-transcription regulation of miRNAs, including that of miR-221/222, whose overexpression has been associated with resistance to tamoxifen $(23,24)$ and fulvestrant (25). Conversely, miR-342-3p levels were revealed to be positively correlated with ER mRNA expression in human BC and associated with tamoxifen sensitivity $(26,27)$. miRNAs that regulate growth, survival, apoptosis, epithelial-mesenchymal transition (EMT) and metastasis of BC cells may be implicated in loss of responsiveness to ET. In particular, PTEN downregulation due to specific miRNAs, permitting abnormal Pi3K/Akt pathway activation, promote estrogen-independent growth and survival of BC cells leading to endocrine treatment resistance $(28,29)$.

Several clinical trials are currently ongoing to evaluate the role of miRNAs as predictive biomarkers in BC. Specifically, trials such as NCT01231386 and NCT01722851, aim to identify circulating miRNAs aiding at the identification of biomarkers of early response to neoadjuvant therapy, including ET, which may be used as potential targets for personalized therapies. Conversely, the NCT01612871 trial was set to explore a panel of circulating miRNAs that could aid to monitor the disease status of the patient while on adjuvant ET (30-32). 


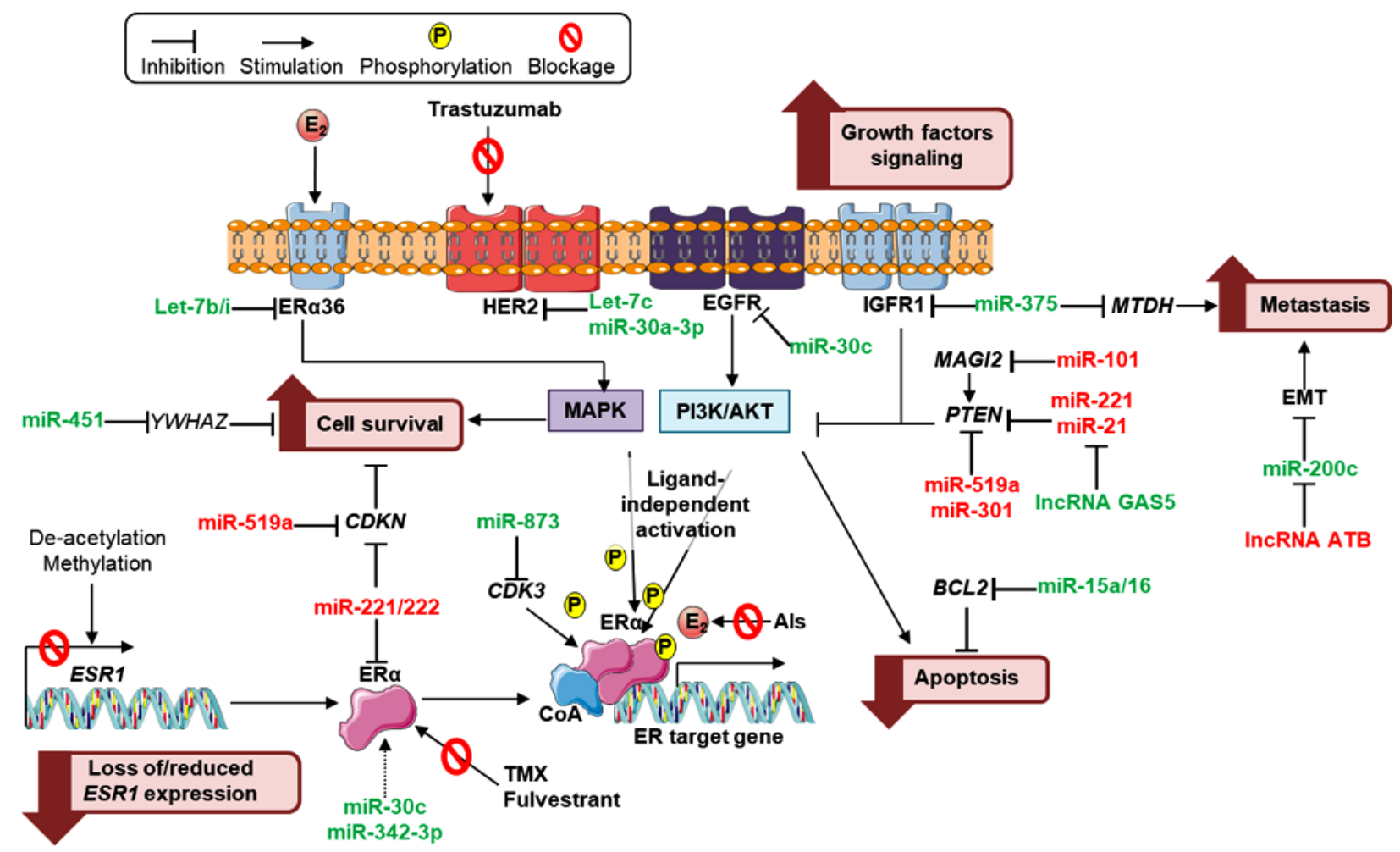

Figure 1. NcRNAs and their established targets involved in endocrine resistance. The ncRNAs and their targets involved in several mechanisms associated with endocrine resistance, along with their functional implication (in pink boxes), including loss of/reduced ESR1 expression, alternative growth-factor signaling inducing downstream signaling, including PI3K/Akt and MAPK signaling pathways, dysregulation of cell survival and apoptosis pathways, and increased metastasis. NcRNAs that confer sensitivity and resistance to endocrine therapies are depicted in green and red, respectively. ER, estrogen receptor; HER2, human epidermal growth factor receptor 2; EGFR, epidermal growth factor receptor; IGFR1, insulin-like growth factor 1 receptor; YWHAZ, tyrosine 3-monooxygenase/tryptophan 5-monooxygenase activation protein $\zeta$; MTDH, metadherin; MAGI2, membrane-associated guanylate kinase inverted 2; PTEN, phosphatase and tensin homolog; EMT, epithelial-mesenchymal transition; CDKN, cyclin-dependent kinase inhibitor; CDK3, cyclin dependent kinase 3; BRCAL2, B-cell CLL/lymphoma 2; PI3K/AKT, phosphoinositide 3-kinase/protein kinase B; ESR1, estrogen receptor 1; TMX, tamoxifen; AIs-aromatase inhibitors; E2, estradiol; miR, microRNA.

Table I. DNA methylation of the promoter region of genes as predictive biomarkers to different modalities of endocrine therapies along with their role and the biological samples used in each study.

\begin{tabular}{|c|c|c|c|c|}
\hline Biomarker & Role & Agent & Samples & Ref. \\
\hline PTEN & Hypermethylation is associated with resistance & TMX & Cell lines & (47) \\
\hline PTGER4 & Hypomethylation is associated with resistance & EDT & & (48) \\
\hline$C D K 10$ & Hypermethylation is associated with shorter PFS and OS & TMX & Cell lines and & (49) \\
\hline $\mathrm{HOXC10}$ & Hypermethylation is associated with resistance & $\begin{array}{l}\text { EDT, AIs } \\
\text { and TMX }\end{array}$ & tumor tissues & $(50)$ \\
\hline ESRI CYPIBI & $\begin{array}{l}\text { High methylation levels are associated } \\
\text { with a better outcome }\end{array}$ & TMX & Tumor tissues & (16) \\
\hline ID4 & Hypomethylation is associated with resistance & & & $(51)$ \\
\hline NAT1 & Hypermethylation is associated with resistance & & & $(52)$ \\
\hline PITX2 & $\begin{array}{l}\text { Hypermethylation is associated with worse } \\
\text { outcome and shorter MFS }\end{array}$ & & & $(21,22,53)$ \\
\hline$P R$ & Hypermethylation is associated with resistance & & & (54) \\
\hline PSAT1 & Hypermethylation is associated with good clinical benefit & & & (55) \\
\hline
\end{tabular}


Table II. Non-coding RNAs involved in response (sensitivity/resistance) to different modalities of endocrine therapies along with their putative targets/mechanism and the biological samples used in each study.

\begin{tabular}{|c|c|c|c|c|c|c|}
\hline ET & Role & miRNA & Putative target & Agent & Samples & Refs. \\
\hline \multirow[t]{28}{*}{ AntiE } & Sensitivity & miR-375 & $M T D H$ & TMX & Cell lines & $(56)$ \\
\hline & & $\operatorname{miR}-873$ & $C D K 3$ & & & (57) \\
\hline & & miR-320a & ARPP19, ESRRG & & & $(58)$ \\
\hline & & Let-7b/i & ESRl & & & \\
\hline & & & (ER- $\alpha 36$ variant) & & & $(59)$ \\
\hline & & $\operatorname{miR}-451$ & $Y W H A Z$ & & & $(60)$ \\
\hline & & $\operatorname{miR}-17 / 20$ & $C C N D 1$ & & & $(61)$ \\
\hline & & miR-148a & $A L C A M$ & & & \\
\hline & & miR-152 & & & & $(62)$ \\
\hline & & $\mathrm{miR}-200 \mathrm{c} / \mathrm{b}$ & $Z E B 1 / 2$ & TMX and FULV & & (63) \\
\hline & & $\mathrm{miR}-15 \mathrm{a} / 16$ & $B R C A L 2$ & TMX & Cell lines and & \\
\hline & & & & & xenografts & (64) \\
\hline & & $\operatorname{miR}-342-3 p$ & BMP7, GEMIN4 & & Cell lines and & \\
\hline & & & & & tumor tissues & $(26)$ \\
\hline & & miR-26a & $E Z H 2$ & & Tumor tissues & $(65)$ \\
\hline & & miR-30c & $E G F R$ & & & $(66)$ \\
\hline & & miR-10a & - & & & \\
\hline & & $\operatorname{miR}-126$ & & & & $(67)$ \\
\hline & Resistance & miR-10b & HDAC4 & TMX & Cell lines & $(68)$ \\
\hline & & $\operatorname{lncRNA}$ & Binding to the & Tumor tissue & & \\
\hline & & DSCAM-AS1 & hnRNPL protein & and cell lines & & $(35)$ \\
\hline & & $\operatorname{miR}-519 a$ & CDKN1A, PTEN, RB1 & & & (29) \\
\hline & & lncRNA BRCAAR4 & - & & & (34) \\
\hline & & $\operatorname{miR}-221 / 222$ & $\begin{array}{l}\text { ESR1, CDKN1B, } \\
C T N N B 1\end{array}$ & TMX and FULV & & $(23,25,69)$ \\
\hline & & miR-301 & $\begin{array}{l}\text { FOXF2, PTEN, } \\
\text { BBRCA3iso2, COL2A1 }\end{array}$ & TMX & $\begin{array}{l}\text { Tumor tissue, cell lines } \\
\text { and xenografts }\end{array}$ & (28) \\
\hline & & $\operatorname{miR}-155$ & SOCS6 & & & $(70)$ \\
\hline & & $\operatorname{miR}-210$ & $E F N A 3, E 2 F 3$ & & Tumor tissue & \\
\hline & & & RAD52, FGFRL1, MET & & & $(71)$ \\
\hline \multirow[t]{5}{*}{ AIs } & Sensitivity & Let-7f & CYP19A1 & LET & Cell lines & $(72)$ \\
\hline & & $\operatorname{miR}-125 b$ & $E R B B 2$ & LET and ANA & Tumor tissues & \\
\hline & & let-7c & & & and cell lines & (73) \\
\hline & Resistance & $\operatorname{miR}-128 \mathrm{a}$ & $T G F B R 1$ & LET & Cell lines & (74) \\
\hline & & miR-181a & BRCAL2L11 & & $\begin{array}{l}\text { Cell lines, xenografts } \\
\text { and tumor tissue }\end{array}$ & $(75)$ \\
\hline
\end{tabular}

miR, microRNA; IncRNA, long non-coding RNA; ET, endocrine therapies; AntiE, anti estrogen; AIs, aromatase inhibitors; ANA, anastrozole; FULV, fulvestrant; DSCAM-AS1, DSCAM antisense RNA 1; BRCAAR4, breast cancer anti-estrogen resistance 4; MTDH, metadherin; CDK, cyclin-dependent kinase; ARPP19, cAMP-regulated phosphoprotein 19; ESRRG, estrogen related receptor gamma; YWHAZ, tyrosine 3-monooxygenase/tryptophan 5-monooxygenase activation protein $\zeta$; CCND1, cyclin D1; ALCAM, activated leukocyte cell adhesion molecule; ZEB, zinc finger E-box-binding homeobox; BRCAL-2, B-cell lymphoma 2; BMP7, bone morphogenetic protein 7; GEMIN4, gem (nuclear organelle)-associated protein 4; EZH2, enhancer of zeste homolog 2; EGFR, epidermal growth factor receptor; HDAC4, histone deacetylase 4; HnRNPL, heterogeneous nuclear ribonucleoprotein L; CDKN, cyclin-dependent kinase inhibitor ; PTEN, phosphatase and tensin homolog; RB1, retinoblastoma 1; ESR1, estrogen receptor 1; CTNNB1, catenin $\beta$ 1; FOXF2, forkhead box F2; BBRCA3iso-2, BRCAL2 binding component 3 isoform 2; COL2A1, collagen type II alpha 1; SOCS, suppressor of cytokine signaling; EFNA3, ephrin A3; E2F3, E2F transcription factor 3; RAD52, RAD52 homolog DNA repair protein; FGFRL1, fibroblast growth factor receptor-like 1; MET, hepatocyte growth factor receptor; CYP19A1, cytochrome P450 family 19 subfamily A member 1; ERBB2, erb-b2 receptor tyrosine kinase 2; TGFBR1, transforming growth factor $\beta$-receptor 1; BRCAL2L11, BRCAL2 like 11; ZNF217, zinc finger protein 217. 
Table III. Chromatin remodeling, post-translational histone modifications and histone variants involved in response (sensitivity/resistance) to endocrine therapies along with their putative epigenetic mechanism and role in response.

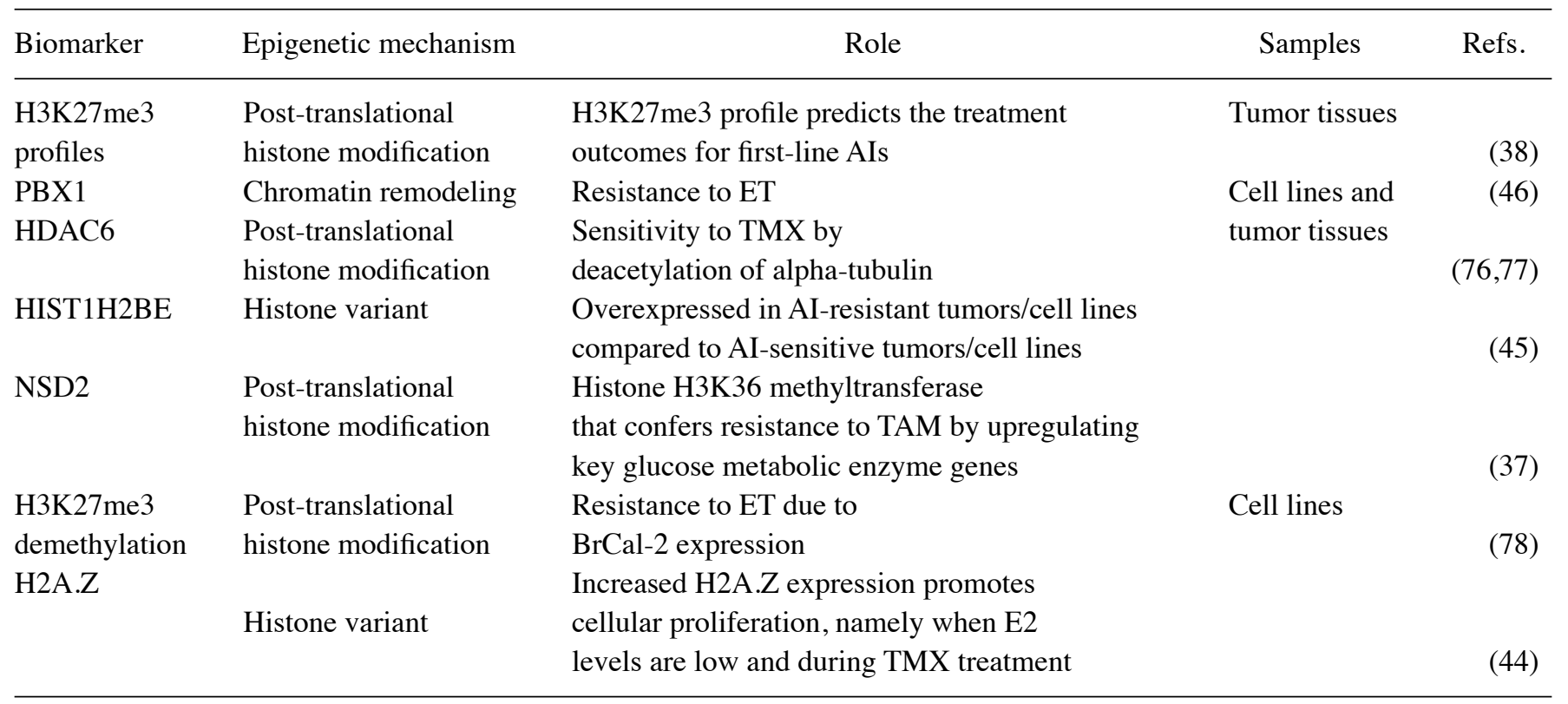

PBX1, PBX homeobox 1; HDAC6, histone deacetylase 6; HIST1H2BE, histone cluster 1 H2B family member E; NSD2, nuclear receptor binding SET domain protein 2; H2A.Z, H2A histone family member Z; ET, endrocrine therapies; TMX, tamoxifen; AIs, aromatase inhibitors.

lncRNAs havealsobeenassociated withendocrine treatment resistance. Particularly, IncRNAs, breast cancer anti-estrogen resistance 4 (BRCAAR4) overexpression $(33,34)$ and DSCAM antisense RNA 1 (DSCAM-AS1) (35), which contains an ER promoter binding motif, have been revealed to predict tamoxifen resistance in primary BC (Table II and Fig. 1).

Chromatin remodeling, post-translational histone modifications and histone variants. Histone post-translation modifications induce chromatin landscape changes that subsequently favor ER repression, thus promoting other signaling pathways that could lead to endocrine resistance, as exemplified by Magnani et al that revealed how the genome's accessibility is altered in drug-resistant vs. drug-responsive BC cells (36). Recently, expression of the H3K36 methyltransferase NSD2 was found to be higher in tamoxifen-resistant BC cell lines, associated with disease recurrence and worse survival (37). Furthermore, H3K37me3 profiles enabled the identification of patients with poor outcome after aromatase inhibitor (AI) treatment (38).

Furthermore, it was recently demonstrated that transcription repression performed by ER co-repressors confer tamoxifen sensitivity through recruitment of HDACs to DNA (39). This evidence suggests that loss of ER co-repressors may sensitize BC cells to the cytotoxic effects of HDACs inhibitors (HDACi). Notably, some clinical trials have demonstrated that HDACi appears to re-establish sensitivity to anti-estrogens in a subset of endocrine treated-resistant tumors $(40,41)$. In addition, the ENCORE-301, a randomized phase II trial (41) tested entinostat, an oral HDACi, in the endocrine-resistance, more specifically AI in post-menopausal women. The results revealed modest improvement in PFS but much greater improvement in overall survival (OS)-median OS improved to 28.1 months in the experimental arm vs. 19.8 months (HR, $0.59 ; 95 \% \mathrm{CI}, 0.36$ to $0.97 ; \mathrm{P}=0.036$ ). Ongoing clinical trials are further testing entinostat in monotherapy or in combination. Moreover, in custom-generated tamoxifen resistant cell lines, treatment with HDACi re-established sensitivity to tamoxifen through significant Bcl-2 downregulation, growth arrest and apoptosis (42).

Histone variants, such as $\mathrm{H} 2 \mathrm{~A} . \mathrm{Z}$, an $\mathrm{H} 2 \mathrm{~A}$ variant, have been shown to be intimately linked to estrogen signaling (43). Notably, a study has already provided a link (yet uncharacterized) between $\mathrm{H} 2 \mathrm{~A} . \mathrm{Z}$ and endocrine resistance by revealing that H2A.Z overexpression led to increased estrogen-independent proliferation (44). Furthermore, another study demonstrated that the histone HIST1H2BE, an H2B variant, was overexpressed not only in endocrine-resistant cell lines, but also in AI-treated tumors from patients which relapsed compared to those that did not (45).

Furthermore, an emerging class of transcription factors named 'pioneer factors', appear to be key players in shaping chromatin structure through binding to chromatin prior to transcription factors, making it accessible for transcription factors, together with histone post-translation modifications and histone variants [68-70]. PBX1 is an example of this class-its expression levels have been associated with reduced metastasis-free survival in ER-positive BC patients (46). Furthermore, a gene expression signature based on NOTCH-PBX1 activity was found to discriminate $\mathrm{BC}$ patients that are responsive to $\mathrm{ET}$ from those which are not. Notably, PBX1 knockdown was sufficient to arrest ER-resistant BC cell growth (36).

These and other chromatin remodeling complexes associated with endocrine resistance are summarized in Table III along with their putative role and the biological samples in which they were characterized. 


\section{Conclusion}

Notwithstanding the prevalence of endocrine treatment resistance in $\mathrm{BC}$, predictive and diagnostic biomarkers in this setting are markedly lacking in clinical practice. In this review, we summarized emerging evidence that epigenetic mechanisms may prove useful for this purpose. These would perform as non-invasive predictive biomarkers of treatment-resistance, providing affordable and sequential monitoring during the course of treatment. The concept of early detection (preclinical) of therapy resistance is compelling, as it could assist clinicians in choosing the most appropriate individualized therapeutic strategy.

Furthermore, some epigenetic modifications in addition to conveying information concerning prediction of response, are also appealingly targetable, in particular due to their reversible nature. The clinical usefulness of these findings, however, is still elusive, mostly due to lack of standardization in methodology, limiting reproducibility.

Promising results have been arising in clinically meaningful trials, such as ENCORE-301. A useful approach would be the integration of the candidate biomarkers into a panel, enabling its validation in a clinical trial setting. Hopefully, this will be accomplished in the near future.

\section{Acknowledgments}

Not applicable.

\section{Funding}

The present study was supported by a grant from the Research Center of Portuguese Oncology Institute of Porto (PI 74-CI-IPOP-19-2016) and the Portuguese Society of Oncology-YOuR Project. SS was supported by a PhD fellowship IPO/ESTIMA-1 NORTE-01-0145FEDER-000027.

\section{Availability of data and materials}

The datasets used during the present study are available from the corresponding author upon reasonable request.

\section{Authors' contributions}

MFS, SPDS, RH and CJ conceived and designed the review. MFS, MA, SS performed the literature search and wrote the manuscript. SPDS, RH and CJ reviewed and edited the manuscript. All authors read and approved the manuscript and agree to be accountable for all aspects of the research in ensuring that the accuracy or integrity of any part of the work are appropriately investigated and resolved.

\section{Ethics approval and consent to participate}

Not applicable.

\section{Patient consent for publication}

Not applicable.

\section{Competing interests}

The authors declare that they have no competing interests.

\section{References}

1. Magnani L, Brunelle M, Gévry N and Lupien M: Chromatin landscape and endocrine response in breast cancer. Epigenomics 4: 675-683, 2012

2. Cheang MC, van de Rijn M and Nielsen TO: Gene expression profiling of breast cancer. Annu Rev Pathol 3: 67-97, 2008.

3. Normanno N, Di Maio M, De Maio E, De Luca A, de Matteis A, Giordano A and Perrone F; NCI-Naple Breast Cancer Group: Mechanisms of endocrine resistance and novel therapeutic strategies in breast cancer. Endocr Relat Cancer 12: 721-747, 2005.

4. Cardoso F, Costa A, Senkus E, Aapro M, André F, Barrios CH Bergh J, Bhattacharyya G, Biganzoli L, Cardoso MJ, et al: 3rd ESO-ESMO international consensus guidelines for Advanced Breast Cancer (ABC 3). Breast 31: 244-259, 2017.

5. Rodríguez-Paredes M and Esteller M: Cancer epigenetics reaches mainstream oncology. Nat Med 17: 330-339, 2011.

6. Jones PA: Functions of DNA methylation: Islands, start sites, gene bodies and beyond. Nat Rev Genet 13: 484-492, 2012.

7. Bannister AJ and Kouzarides T: Regulation of chromatin by histone modifications. Cell Res 21: 381-395, 2011.

8. Zentner GE and Henikoff S: Regulation of nucleosome dynamics by histone modifications. Nat Struct Mol Biol 20: 259-266, 2013.

9. Amorim M, Salta S, Henrique R and Jerónimo C: Decoding the usefulness of non-coding RNAs as breast cancer markers. J Transl Med 14: 265, 2016.

10. Kung JT, Colognori D and Lee JT: Long noncoding RNAs: Past, present, and future. Genetics 193: 651-669, 2013.

11. Huntzinger $E$ and Izaurralde $E$ : Gene silencing by microRNAs: Contributions of translational repression and mRNA decay. Nat Rev Genet 12: 99-110, 2011.

12. Sharma D, Blum J, Yang X, Beaulieu N, Macleod AR and Davidson NE: Release of methyl $\mathrm{CpG}$ binding proteins and histone deacetylase 1 from the estrogen receptor $\alpha$ (ER) promoter upon reactivation in ER-negative human breast cancer cells. Mol Endocrinol 19: 1740-1751, 2005.

13. Heyn $\mathrm{H}$ and Esteller M: DNA methylation profiling in the clinic: Applications and challenges. Nat Rev Genet 13: 679-692, 2012.

14. Jerónimo $C$ and Henrique R: Epigenetic biomarkers in urological tumors: A systematic review. Cancer Lett 342: 264-274, 2014.

15. Costa-Pinheiro P, Montezuma D, Henrique R and Jerónimo C: Diagnostic and prognostic epigenetic biomarkers in cancer. Epigenomics 7: 1003-1015, 2015.

16. Widschwendter M, Siegmund KD, Müller HM, Fiegl H, Marth C, Müller-Holzner E, Jones PA and Laird PW: Association of breast cancer DNA methylation profiles with hormone receptor status and response to tamoxifen. Cancer Res 64: 3807-3813, 2004.

17. Fan M, Yan PS, Hartman-Frey C, Chen L, Paik H, Oyer SL, Salisbury JD, Cheng AS, Li L, Abbosh PH, et al: Diverse gene expression and DNA methylation profiles correlate with differential adaptation of breast cancer cells to the antiestrogens tamoxifen and fulvestrant. Cancer Res 66: 11954-11966, 2006.

18. Musgrove EA and Sutherland RL: Biological determinants of endocrine resistance in breast cancer. Nat Rev Cancer 9: 631-643, 2009.

19. Stone A, Zotenko E, Locke WJ, Korbie D, Millar EK, Pidsley R, Stirzaker C, Graham P, Trau M, Musgrove EA, et al: DNA methylation of oestrogen-regulated enhancers defines endocrine sensitivity in breast cancer. Nat Commun 6: 7758, 2015.

20. Williams KE, Anderton DL, Lee MP, Pentecost BT and Arcaro KF: High-density array analysis of DNA methylation in Tamoxifen-resistant breast cancer cell lines. Epigenetics 9: 297-307, 2014.

21. Maier S, Nimmrich I, Koenig T, Eppenberger-Castori S, Bohlmann I, Paradiso A, Spyratos F, Thomssen C, Mueller V, Nährig J, et al; European Organisation for Research and Treatment of Cancer (EORTC) PathoBiology group: DNA-methylation of the homeodomain transcription factor PITX2 reliably predicts risk of distant disease recurrence in tamoxifen-treated, node-negative breast cancer patients: Technical and clinical validation in a multi-centre setting in collaboration with the European Organisation for Research and Treatment of Cancer (EORTC) PathoBiology group. Eur J Cancer 43: 1679-1686, 2007. 
22. Harbeck N, Nimmrich I, Hartmann A, Ross JS, Cufer T, Grützmann R, Kristiansen G, Paradiso A, Hartmann O, Margossian A, et al: Multicenter study using paraffin-embedded tumor tissue testing PITX2 DNA methylation as a marker for outcome prediction in tamoxifen-treated, node-negative breast cancer patients. J Clin Oncol 26: 5036-5042, 2008.

23. Miller TE, Ghoshal K, Ramaswamy B, Roy S, Datta J, Shapiro CL, Jacob S and Majumder S: MicroRNA-221/222 confers tamoxifen resistance in breast cancer by targeting p $27^{\mathrm{Kipl}}$. J Biol Chem 283 29897-29903, 2008.

24. Zhao JJ, Lin J, Yang H, Kong W, He L, Ma X, Coppola D and Cheng JQ: MicroRNA-221/222 negatively regulates estrogen receptor $\alpha$ and is associated with tamoxifen resistance in breast cancer. J Biol Chem 283: 31079-31086, 2008

25. Rao X, Di Leva G, Li M, Fang F, Devlin C, Hartman-Frey C, Burow ME, Ivan M, Croce CM and Nephew KP: MicroRNA-221/222 confers breast cancer fulvestrant resistance by regulating multiple signaling pathways. Oncogene 30: 1082-1097, 2011.

26. Cittelly DM, Das PM, Spoelstra NS, Edgerton SM, Richer JK, Thor AD and Jones FE: Downregulation of miR-342 is associated with tamoxifen resistant breast tumors. Mol Cancer 9: 317, 2010.

27. He YJ, Wu JZ, Ji MH, Ma T, Qiao EQ, Ma R and Tang JH: miR-342 is associated with estrogen receptor- $\alpha$ expression and response to tamoxifen in breast cancer. Exp Ther Med 5: 813-818, 2013

28. Shi W, Gerster K, Alajez NM, Tsang J, Waldron L, Pintilie M, Hui AB, Sykes J, P'ng C, Miller N, et al: MicroRNA-301 mediates proliferation and invasion in human breast cancer Cancer Res 71: 2926-2937, 2011.

29. Ward A, Shukla K, Balwierz A, Soons Z, König R, Sahin O and Wiemann S: MicroRNA-519a is a novel oncomir conferring tamoxifen resistance by targeting a network of tumour-suppressor genes in $\mathrm{ER}^{+}$breast cancer. J Pathol 233: 368-379, 2014

30. ClinicalTrials.gov: MIRNA Profiling of Breast Cancer in Patients Undergoing Neoadjuvant or Adjuvant Treatment for Locally Advanced \& Inflammatory Breast Cancer. ClinicalTrials. gov2016. https://clinicaltrials.gov/ct2/show/NCT01231386.

31. ClinicalTrials.gov: Circulating miRNAs. ICORG 10-11, V2 ClinicalTrials.gov2017. https://clinicaltrials.gov/ct2/show/ NCT01722851.

32. ClinicalTrials gov: Circulating miRNAs as Biomarkers of Hormone Sensitivity in Breast Cancer (MIRHO). ClinicalTrials. gov2014. https://clinicaltrials.gov/ct2/show/NCT01612871.

33. Meijer D, van Agthoven T, Bosma PT, Nooter K and Dorssers LC: Functional screen for genes responsible for tamoxifen resistance in human breast cancer cells. Mol Cancer Res 4: 379-386, 2006.

34. Godinho MF, Sieuwerts AM, Look MP, Meijer D, Foekens JA, Dorssers LC and Van Agthoven T: Relevance of BCAR4 in tamoxifen resistance and tumour aggressiveness of human breast cancer. Br J Cancer 103: 1284-1291, 2010.

35. Niknafs YS, Han S, Ma T, Speers C, Zhang C, Wilder-Romans K, Iyer MK, Pitchiaya S, Malik R, Hosono Y, et al: The lncRNA landscape of breast cancer reveals a role for DSCAM-AS1 in breast cancer progression. Nat Commun 7: 12791, 2016.

36. Magnani L, Stoeck A, Zhang X, Lánczky A, Mirabella AC, Wang TL, Gyorffy B and Lupien M: Genome-wide reprogramming of the chromatin landscape underlies endocrine therapy resistance in breast cancer. Proc Natl Acad Sci USA 110: E1490-E1499, 2013

37. Wang J, Duan Z, Nugent Z, Zou JX, Borowsky AD, Zhang Y, Tepper CG, Li JJ, Fiehn O, Xu J, et al: Reprogramming metabolism by histone methyltransferase NSD2 drives endocrine resistance via coordinated activation of pentose phosphate pathway enzymes. Cancer Lett 378: 69-79, 2016.

38. Jansen MP, Knijnenburg T, Reijm EA, Simon I, Kerkhoven R, Droog M, Velds A, van Laere S, Dirix L, Alexi X, et al: Hallmarks of aromatase inhibitor drug resistance revealed by epigenetic profiling in breast cancer. Cancer Res 73: 6632-6641, 2013

39. Légaré $S$ and Basik M: Minireview: The link between ERo corepressors and histone deacetylases in tamoxifen resistance in breast cancer. Mol Endocrinol 30: 965-976, 2016.

40. Munster PN, Thurn KT, Thomas S, Raha P, Lacevic M, Miller A, Melisko M, Ismail-Khan R, Rugo H, Moasser M, et al: A phase II study of the histone deacetylase inhibitor vorinostat combined with tamoxifen for the treatment of patients with hormone therapy-resistant breast cancer. Br J Cancer 104: $1828-1835,2011$
41. Yardley DA, Ismail-Khan RR, Melichar B, Lichinitser M, Munster PN, Klein PM, Cruickshank S, Miller KD, Lee MJ and Trepel JB: Randomized phase II, double-blind, placebo-controlled study of exemestane with or without entinostat in postmenopausal women with locally recurrent or metastatic estrogen receptor-positive breast cancer progressing on treatment with a nonsteroidal aromatase inhibitor. J Clin Oncol 31: 2128-2135, 2013.

42. Raha P, Thomas S, Thurn KT, Park J and Munster PN: Combined histone deacetylase inhibition and tamoxifen induces apoptosis in tamoxifen-resistant breast cancer models, by reversing Bcl-2 overexpression. Breast Cancer Res 17: 26, 2015.

43. Gévry N, Hardy S, Jacques P-É,Laflamme L, Svotelis A, Robert F and Gaudreau L: Histone H2A.Z is essential for estrogen receptor signaling. Genes Dev 23: 1522-1533, 2009.

44. Svotelis A, Gévry N, Grondin G and Gaudreau L: H2A.Z overexpression promotes cellular proliferation of breast cancer cells. Cell Cycle 9: 364-370, 2010.

45. Nayak SR, Harrington E, Boone D, Hartmaier R, Chen J, Pathiraja TN,CooperKL,Fine JL,Sanfilippo J, Davidson NE, et al: A role for histone $\mathrm{H} 2 \mathrm{~B}$ variants in endocrine-resistant breast cancer. Horm Cancer 6: 214-224, 2015.

46. Magnani L, Ballantyne EB, Zhang X and Lupien M: PBX1 genomic pioneer function drives ER $\alpha$ signaling underlying progression in breast cancer. PLoS Genet 7: e1002368, 2011.

47. Phuong NT, Kim SK, Lim SC, Kim HS, Kim TH, Lee KY, Ahn SG, Yoon JH and Kang KW: Role of PTEN promoter methylation in tamoxifen-resistant breast cancer cells. Breast Cancer Res Treat 130: 73-83, 2011.

48. Hiken JF, McDonald JI, Decker KF, Sanchez C, Hoog J, VanderKraats ND, Jung KL, Akinhanmi M, Rois LE, Ellis MJ, et al: Epigenetic activation of the prostaglandin receptor EP4 promotes resistance to endocrine therapy for breast cancer. Oncogene 36: 2319-2327, 2017.

49. Iorns E, Turner NC, Elliott R, Syed N, Garrone O, Gasco M, Tutt AN, Crook T, Lord CJ and Ashworth A: Identification of CDK10 as an important determinant of resistance to endocrine therapy for breast cancer. Cancer Cell 13: 91-104, 2008.

50. Pathiraja TN, Nayak SR, Xi Y, Jiang S, Garee JP, Edwards DP, Lee AV, Chen J, Shea MJ, Santen RJ, et al: Epigenetic reprogramming of HOXC10 in endocrine-resistant breast cancer. Sci Transl Med 6: 229ra41, 2014.

51. Zhang Y, Zhang B, Fang J and Cao X: Hypomethylation of DNA-binding inhibitor 4 serves as a potential biomarker in distinguishing acquired tamoxifen-refractory breast cancer. Int J Clin Exp Pathol 8: 9500-9505, 2015

52. Kim SJ, Kang HS, Jung SY, Min SY, Lee S, Kim SW, Kwon Y, Lee KS, Shin KH and Ro J: Methylation patterns of genes coding for drug-metabolizing enzymes in tamoxifen-resistant breast cancer tissues. J Mol Med 88: 1123-1131, 2010.

53. Nimmrich I, Sieuwerts AM, Meijer-van Gelder ME, Schwope I, Bolt-de Vries J, Harbeck N, Koenig T, Hartmann O, Kluth A, Dietrich D, et al: DNA hypermethylation of PITX2 is a marker of poor prognosis in untreated lymph node-negative hormone receptor-positive breast cancer patients. Breast Cancer Res Treat 111: 429-437, 2008

54. Pathiraja TN, Shetty PB, Jelinek J, He R, Hartmaier R, Margossian AL, Hilsenbeck SG, Issa JP and Oesterreich S: Progesterone receptor isoform-specific promoter methylation: Association of $P R A$ promoter methylation with worse outcome in breast cancer patients. Clin Cancer Res 17: 4177-4186, 2011.

55. Martens JW, Nimmrich I, Koenig T, Look MP, Harbeck N, Model F, Kluth A, Bolt-de Vries J, Sieuwerts AM, Portengen H, et al: Association of DNA methylation of phosphoserine aminotransferase with response to endocrine therapy in patients with recurrent breast cancer. Cancer Res 65: 4101-4117, 2005.

56. Ward A, Balwierz A, Zhang JD, Küblbeck M, Pawitan Y, Hielscher T, Wiemann S and Sahin Ö: Re-expression of microRNA-375 reverses both tamoxifen resistance and accompanying EMT-like properties in breast cancer. Oncogene 32: 1173-1182, 2013.

57. Cui J, Yang Y, Li H, Leng Y, Qian K, Huang Q, Zhang C, Lu Z, Chen J, Sun T, et al: MiR-873 regulates ER $\alpha$ transcriptional activity and tamoxifen resistance via targeting CDK3 in breast cancer cells. Oncogene 34: 3895-3907, 2015.

58. Lü M, Ding K, Zhang G, Yin M, Yao G, Tian H, Lian J, Liu L, Liang M, Zhu T, et al: MicroRNA-320a sensitizes tamoxifen-resistant breast cancer cells to tamoxifen by targeting ARPP-19 and ERR $\gamma:$ Sci Rep 4: 8735, 2015. 
59. Zhao Y, Deng C, Lu W, Xiao J, Ma D, Guo M, Recker RR, Gatalica Z, Wang Z and Xiao GG: let-7 microRNAs induce tamoxifen sensitivity by downregulation of estrogen receptor $\alpha$ signaling in breast cancer. Mol Med 17: 1233-1241, 2011.

60. Bergamaschi A and Katzenellenbogen BS: Tamoxifen downregulation of miR-451 increases 14-3-3 $\zeta$ and promotes breast cancer cell survival and endocrine resistance. Oncogene 31: $39-47,2012$.

61. Yu Z, Xu Z, Disante G, Wright J, Wang M, Li Y, Zhao Q, Ren T, Ju X, Gutman E, et al: miR-17/20 sensitization of breast cancer cells to chemotherapy-induced apoptosis requires Akt1. Oncotarget 5: 1083-1090, 2014.

62. Chen MJ, Cheng YM, Chen CC, Chen YC and Shen CJ: MiR-148a and $\mathrm{miR}-152$ reduce tamoxifen resistance in $\mathrm{ER}^{+}$breast cancer via downregulating ALCAM. Biochem Biophys Res Commun 483: 840-846, 2017.

63. Manavalan TT, Teng Y, Litchfield LM, Muluhngwi P, Al-Rayyan N and Klinge CM: Reduced expression of miR-200 family members contributes to antiestrogen resistance in LY2 human breast cancer cells. PLoS One 8: e62334, 2013.

64. Cittelly DM, Das PM, Salvo VA, Fonseca JP, Burow ME and Jones FE: Oncogenic HER2\{Delta\}16 suppresses miR-15a/16 and deregulates BCL-2 to promote endocrine resistance of breast tumors. Carcinogenesis 31: 2049-2057, 2010

65. Jansen MP, Reijm EA, Sieuwerts AM, Ruigrok-Ritstier K, Look MP, Rodríguez-González FG, Heine AA, Martens JW, Sleijfer S, Foekens JA, et al: High miR-26a and low CDC2 levels associate with decreased EZH2 expression and with favorable outcome on tamoxifen in metastatic breast cancer. Breast Cancer Res Treat 133: 937-947, 2012.

66. Rodríguez-González FG, Sieuwerts AM, Smid M, Look MP Meijer-van Gelder ME, de Weerd V, Sleijfer S, Martens JW and Foekens JA: MicroRNA-30c expression level is an independent predictor of clinical benefit of endocrine therapy in advanced estrogen receptor positive breast cancer. Breast Cancer Res Treat 127: 43-51, 2011.

67. Hoppe R, Achinger-Kawecka J, Winter S, Fritz P, Lo WY, Schroth W and Brauch H: Increased expression of miR-126 and miR-10a predict prolonged relapse-free time of primary oestrogen receptor-positive breast cancer following tamoxifen treatment. Eur J Cancer 49: 3598-3608, 2013.

68. Ahmad A, Ginnebaugh KR, Yin S, Bollig-Fischer A, Reddy KB and Sarkar FH: Functional role of miR-10b in tamoxifen resistance of ER-positive breast cancer cells through downregulation of HDAC4. BMC Cancer 15: 540, 2015.
69. Wei Y, Lai X, Yu S, Chen S, Ma Y, Zhang Y, Li H, Zhu X, Yao L and Zhang J: Exosomal miR-221/222 enhances tamoxifen resistance in recipient ER-positive breast cancer cells. Breast Cancer Res Treat 147: 423-431, 2014.

70. Shen R, Wang Y, Wang CX, Yin M, Liu HL, Chen JP, Han JQ and Wang WB: MiRNA- 155 mediates TAM resistance by modulating SOCS6-STAT3 signalling pathway in breast cancer. Am J Transl Res 7: 2115-2126, 2015.

71. Rothé F, Ignatiadis M, Chaboteaux C, Haibe-Kains B, Kheddoumi N, Majjaj S, Badran B, Fayyad-Kazan H, Desmedt C, Harris AL, et al: Global microRNA expression profiling identifies MiR-210 associated with tumor proliferation, invasion and poor clinical outcome in breast cancer. PLoS One 6: e20980, 2011

72. Shibahara Y, Miki Y, Onodera Y, Hata S, Chan MS, Yiu CC, Loo TY, Nakamura Y, Akahira J, Ishida T, et al: Aromatase inhibitor treatment of breast cancer cells increases the expression of let-7f, a microRNA targeting CYP19A1. J Pathol 227: 357-366, 2012.

73. Bailey ST, Westerling T and Brown M: Loss of estrogen-regulated microRNA expression increases HER2 signaling and is prognostic of poor outcome in luminal breast cancer. Cancer Res 75: 436-445, 2015.

74. Masri S, Liu Z, Phung S, Wang E, Yuan YC and Chen S: The role of microRNA-128a in regulating TGFbeta signaling in letrozole-resistant breast cancer cells. Breast Cancer Res Treat 124: 89-99, 2010.

75. Hayes EL and Lewis-Wambi JS: Mechanisms of endocrine resistance in breast cancer: An overview of the proposed roles of noncoding RNA. Breast Cancer Res 17: 40, 2015.

76. Zhang Z, Yamashita H, Toyama T, Sugiura H, Omoto Y, Ando Y, Mita K, Hamaguchi M, Hayashi S and Iwase H: HDAC6 expression is correlated with better survival in breast cancer. Clin Cancer Res 10: 6962-6968, 2004.

77. Saji S, Kawakami M, Hayashi S, Yoshida N, Hirose M, Horiguchi S, Itoh A, Funata N, Schreiber SL, Yoshida M, et al: Significance of HDAC6 regulation via estrogen signaling for cell motility and prognosis in estrogen receptor-positive breast cancer. Oncogene 24: 4531-4539, 2005.

78. Svotelis A, Bianco S, Madore J, Huppé G, Nordell-Markovits A, Mes-Masson AM and Gévry N: H3K27 demethylation by JMJD3 at a poised enhancer of anti-apoptotic gene $B C L 2$ determines ER $\alpha$ ligand dependency. EMBO J 30: 3947-3961, 2011. 